\title{
Ikaros integrates endocrine and immune system development
}

\author{
Shereen Ezzat, ${ }^{1,2}$ Rene Mader, ${ }^{2,3}$ ShunJiang Yu, ${ }^{1,2}$ Terry Ning, ${ }^{4}$ \\ Philippe Poussier, ${ }^{4}$ and Sylvia L. Asa ${ }^{2,3}$
}

\begin{abstract}
1Department of Medicine, Mount Sinai Hospital and University of Toronto, Toronto, Ontario, Canada. ${ }^{2}$ The Freeman Centre for Endocrine Oncology and The Ontario Cancer Institute, Toronto, Ontario, Canada. ${ }^{3}$ Department of Pathology, University Health Network and University of Toronto, Toronto, Ontario, Canada. ${ }^{4}$ Sunnybrook and Women's Health Sciences Centre, Toronto, Ontario, Canada.
\end{abstract}

\begin{abstract}
Ikaros transcription factors are essential regulators of lymphopoiesis and the development of the immune system. We now show that Ikaros is expressed in hormone-producing pituitary corticomelanotroph cells, where it binds the proopiomelanocortin promoter and regulates endogenous gene expression. Loss of Ikaros in vivo results in contraction of the pituitary corticomelanotroph population, reduced circulating adrenocorticotrophic hormone levels, and adrenal glucocorticoid insufficiency. While hemopoietic reconstitution failed to correct this hormonal deficit, the phenotype of reduced body weight and diminished survival was rescued by systemic glucocorticoid-hormone administration. Given the established immunomodulatory properties of glucocorticoid hormones, these findings reveal a novel role for Ikaros in orchestrating immune-endocrine development and function.
\end{abstract}

\section{Introduction}

Increasing evidence supports the existence of a functional network of distinct signals at the interface between the immune and endocrine systems that coordinate neuroendocrine stress responses (1). Most of the interconnections between these 2 systems have been identified at the level of cytokine action. Inflammatory cytokines modulate the output of the principal product of pituitary corticotrophs, the prohormone proopiomelanocortin (POMC), which is cleaved into adrenocorticotrophic hormone (ACTH), which in turn has immunomodulatory effects $(1,2)$.

The process of pituitary hormone regulation is dependent on a number of cis- and trans-active elements that are necessary for tissue-specific gene expression. Several transcription-regulating proteins identified in the pituitary have been implicated as key elements in the definition of cell-specific phenotypes and the regulation of hormone genes uniquely expressed by these cells $(3,4)$. Which of the lineage-regulating factors predominates in determining the lineage and cell population expansion can be decided not only by exogenous regulatory substances (3) but possibly also by epigenetic factors that alter the chromatin accessibility at their cognate sites.

Ikaros was initially described as a transcription factor that recognizes regulatory sequences of genes expressed in lymphoid cells $(5,6)$. The Ikaros gene undergoes alternative splicing to generate at least 8 isoforms, Ik1-Ik8. The $\mathrm{N}$-terminal region includes zinc finger motifs that bind DNA. Alternatively, spliced isoforms lacking the $\mathrm{N}$-terminus but retaining the $\mathrm{C}$-terminus form inactive heterodimers. The various isoforms can act either as activators or repressors in a functionally diverse chromatin remodeling network (5).

Nonstandard abbreviations used: ACTH, adrenocorticotrophic hormone; FGFR4, fibroblast growth factor receptor 4; HDAC, histone deacetylase; POMC, proopiomelanocortin.

Conflict of interest: The authors have declared that no conflict of interest exists.

Citation for this article: J. Clin. Invest. 115:1021-1029 (2005).

doi:10.1172/JCI200522486
We recently identified expression of Ikaros in the mouse pituitary (7), where it is thought to play a role in regulation of fibroblast growth factor receptor 4 (FGFR4), a gene also expressed by hematopoietic elements (8). Altered expression of Ikaros isoforms is also implicated in human pituitary tumorigenesis through its actions on FGFR4 transcription $(9,10)$. In this report, we identify Ikaros expression by POMC-producing pituitary corticomelanotroph cells and demonstrate a direct role for Ikaros in the regulation of ACTH expression and adrenocortical hormone output. The data unmask a critical contribution of Ikaros in pituitary gland development and function as part of a network that has previously been regarded as nearly exclusive to the immune system.

\section{Results}

Pituitary corticomelanotroph cells express Ikaros. Using Northern blotting, we detected an Ikaros mRNA doublet of approximately $2.7 \mathrm{~kb}$ in mouse corticomelanotroph AtT20 cells. This product corresponds to the expected size of $I k 1$ and $I k 2 \mathrm{mRNA}$ isoforms. It comigrated with and was of a similar level of expression to the product derived from pro-B lymphocytes, which represent the principal source of Ikaros (Figure 1A). The Ikaros mRNA transcripts were translated, as demonstrated by Western immunoblotting (Figure 1B). Moreover, a weak mRNA transcript encoding the Ikaros-related factor Eos was detected in pituitary corticomelanotroph cells by Northern blotting (Figure 1A), and this protein was also detected in these cells by Western blotting (Figure 1B).

The expression of Ikaros by pituitary corticomelanotroph cells was also examined by EMSA. Using an Ikaros consensus oligonucleotide as a probe, we found that nuclear extracts from AtT20 corticotroph cells formed specific DNA-protein complexes (Figure 1C). These complexes were competed and supershifted in a manner similar to those formed by nuclear extracts from pro-B lymphocytes (Figure 1C). The same complex in lymphocytes and in pituitary AtT20 cells was supershifted by an Eos antibody.

The pituitary POMC gene contains functional Ikaros binding sites. Having identified Ikaros expression in pituitary corticomelanotrophs, we examined whether the major pituitary hormone gene 
A

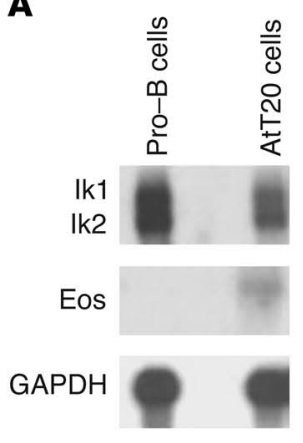

B

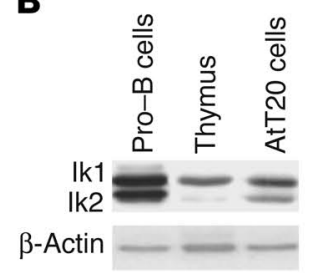

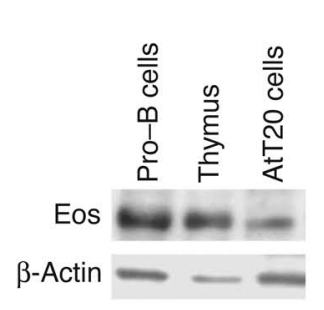

C

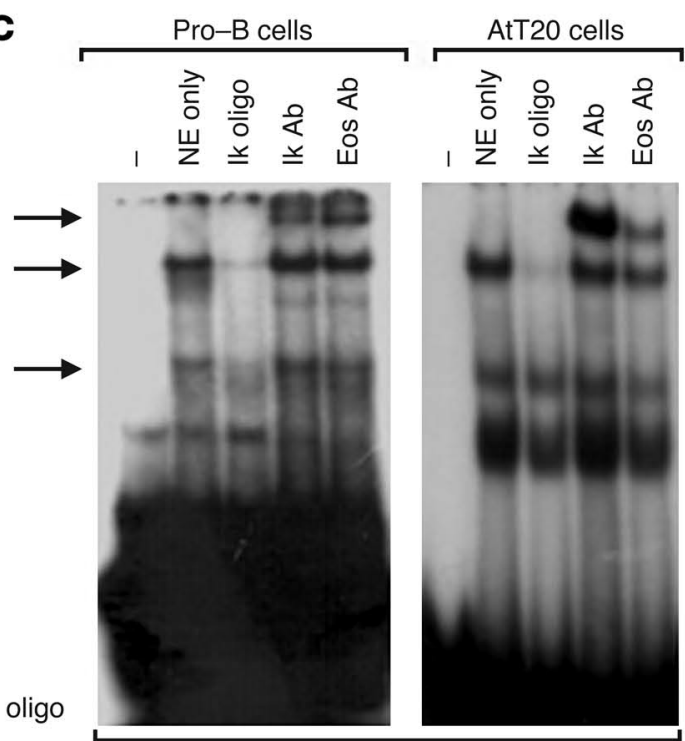

Ik oligo

Figure 1

Identification of Ikaros and Eos expression in pituitary corticotroph cells. (A) Northern blotting of polyA RNA from pituitary corticomelanotroph AtT20 pituitary cells using Ikaros cDNA (top) identifies a doublet transcript of 2.7 and $2.5 \mathrm{~kb}$, consistent with $I \mathrm{k} 1$ and $I \mathrm{k} 2 \mathrm{mRNA}$ expression. This doublet comigrates with that from pro-B lymphocyte-derived RNA. Eos mRNA expression (middle) is detected at much lower levels in AtT20 cells. The GAPDH loading control is shown immediately below. (B) Western blotting using specific antibodies against Ikaros (left) identifies a 52- and 50-kDa doublet that comigrates with that from lymphocytes. Detection with anti-Eos antibody (right) identifies the predicted 57-kDa product in AtT20 cells. The corresponding $\beta$-actin loading controls are shown immediately below. (C) Detection of Ikaros by EMSA of a DNA fragment including the Ikaros consensus binding motif, which binds nuclear extracts (NE) from pituitary corticomelanotroph AtT20 similar to those from pro-B lymphocytes. DNA-protein complexes from pituitary AtT20 cells are competed by $100 \mathrm{M}$ excess of wild-type Ikaros oligonucleotide (Ik oligo) and are supershifted by antibody against Ikaros (arrows) and to a lesser extent by an antibody against Eos.

expressed by these cells represents a transcriptional target for Ikaros. To determine whether Ikaros can recognize a specific element in the POMC promoter, we screened potential Ikarosbinding domains of the POMC promoter using EMSA. We used nuclear extracts from corticotroph AtT20 cells with overlapping oligonucleotide fragments containing all 5 potential Ikaros-binding sites in the mouse POMC promoter (Figure 2A). DNA-protein complexes were detected when extracts were incubated with 3 fragments containing putative Ikaros-binding sites, fragments A $(-451 /-420)$, B $(-163 /-137)$, and C $(-118 /-89)$ (Figure 2B). Formation of these DNA-protein complexes was abolished by excess unlabeled wild-type Ikaros oligonucleotide (Figure 2C) but not by mutant Ikaros or non-Ikaros (Sp1, Ap-1, Ap-2) oligonucleotides (data not shown). Further, these complexes were supershifted by Ikaros antibody in a dose-responsive manner (Figure 2C) and to a lesser extent by Eos antibody (Figure 2C) but not by other control antibodies, including those against $\mathrm{Rb}$, Pit-1, and Sp1. Mutation of the Ikaros binding sites A, B, and C of the POMC promoter resulted in failure to form specific complexes when the probe was incubated with pituitary AtT20 or pro-B lymphocyte nuclear extracts (data not shown).

Ikaros binds the POMC promoter and regulates gene expression. We tested the response of the wild-type $\mathrm{P}(-543)$-Luc POMC promoter to cotransfection with Ik1 or the Ikaros dominant negative (nonDNA-binding) Ik6 isoform. Figure 3A demonstrates the ability of Ik1 to activate the POMC promoter in AtT20 cells, according to a luciferase reporter assay. In contrast, transfection of Ik6 repressed $P O M C$ promoter activity, which is consistent with functional antagonism between the 2 Ikaros isoforms. Transfection of the related family member Eos also resulted in modest (approximately $25 \%$ ) attenuation of $P O M C$ promoter activity.

To determine the functional significance of the Ikaros-binding sites in the $P O M C$ promoter, we individually mutated each of these sites. Disruption of binding site A or B but not site $\mathrm{C}$ resulted in appreciable loss of $P O M C$ promoter activity (Figure 3A). The effects of Ik1 overexpression were abolished by mutation of site A or B but were not affected by mutation of site C. These data are consistent with the lack of efficient competition by the Ikaros oligonucleotide of the site $\mathrm{C}$ complex, which indicates a minimal contribution from site $\mathrm{C}$ to $P O M C$ promoter activity.

Stable transfection of $\mathrm{Ik} 1$ resulted in enhanced endogenous $P O M C$ gene expression as determined by Northern blotting of independent, stably transfected clones (Figure 3B). In contrast, cells stably transfected with either Ik6 or Eos demonstrated reduced POMC mRNA levels. Immunoassay measurements of ACTH in conditioned culture media revealed a nearly 5 -fold increase in ACTH secretion by AtT 20 cells stably transfected with Ik 1 compared with empty vector-, Ik6-, or Eos-transfected cells (Figure 3C). Taken together, these data provide evidence of a role for Ikaros in pituitary POMC gene regulation.

Loss of Ikaros disrupts pituitary corticomelanotroph development. To examine the effect of Ikaros on pituitary corticomelanotroph development, we systematically examined the pituitary glands of mice with disruption of the Ikaros gene. Animals were examined at the earliest stages of expected corticomelanotroph differentiation and subsequent stages of late fetal development 
A

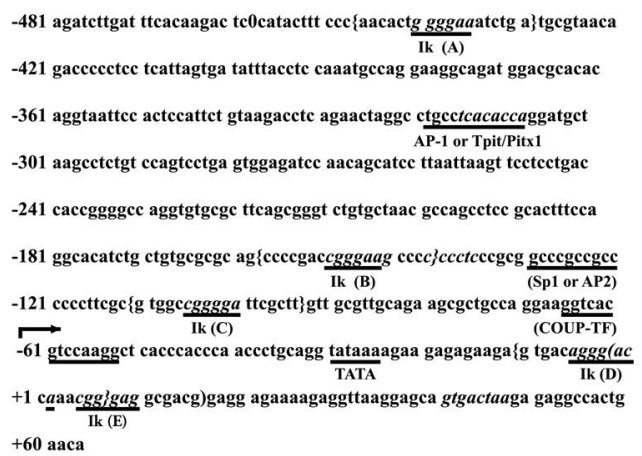
+60 aaca

C

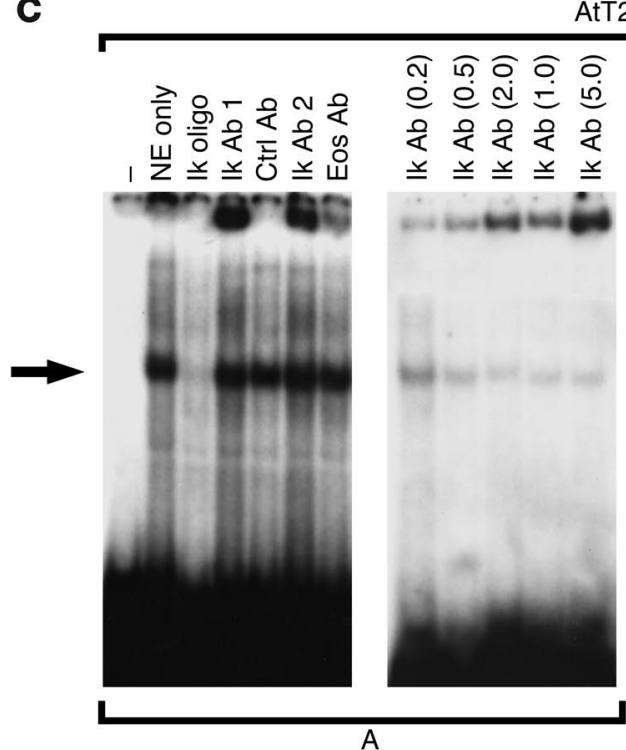

AtT20 cells

B

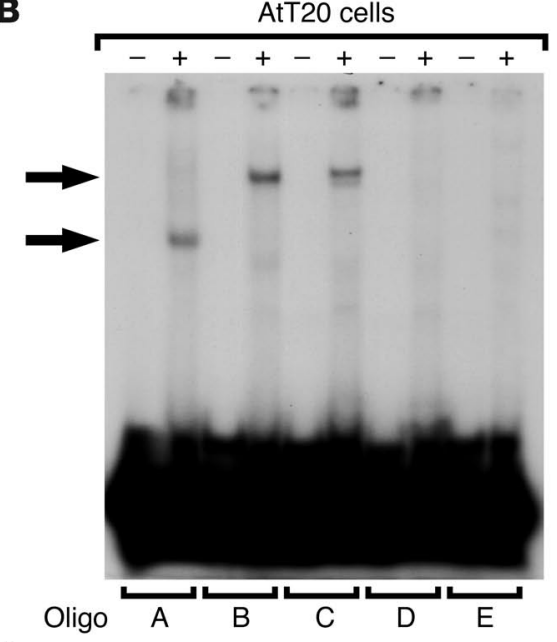

\section{Figure 2}

Characterization of Ikaros-type transcription factor-binding elements in the POMC gene promoter. (A) Potential lkaros-type binding sites in the $P O M C-543$ promoter were determined with TRANSFAC software. Five potential sites, indicated by $A, B, C, D$ and $E$, were identified. Other recognized transcription factor-binding elements are indicated. (B) The 5 POMC promoter Ikarosbinding sites were used as EMSA probes with nuclear extracts from AtT20 cells. Note complex formation with fragments $A, B$, and $C$ but not $D$ and $E$. Reactions without (-) and with (+) nuclear protein are indicated. (C) Oligonucleotides A, B, and C were further tested in the absence or presence of $100 \mathrm{M}$ excess Ikaros oligonucleotide or a monoclonal antibody against Ikaros (Ik Ab 1), a polyclonal antiserum against Ikaros (Ik Ab 2), Eos (Eos $A b)$, and a control antibody (Ctrl $\mathrm{Ab}$ ) against $\mathrm{Rb}$ as indicated. As noted in $\mathbf{B}$, the site $\mathbf{A}$ complex runs faster than those generated by $B$ or C. The supershifted bands with the antibody against lkaros are uniformly more intense and migrate slightly higher than those with the antibody against Eos. Increased amounts ( $\mu \mathrm{l}$ ) of Ikaros antiserum (second panel) result in increased intensity of the supershifted bands. into adulthood. At E15.5, developing corticomelanotroph cells were identified by Tpit expression at the periphery of the gland as previously described (11). At E17.5, POMC expression was reduced in Ikaros-heterozygous mice and was almost undetectable in Ikaros-null (-/-) mice despite the presence of normal Tpit expression (Figure 4A).

The contraction of the corticomelanotroph population persisted into postnatal life with reduction of corticomelanotrophs in Ikaros-null animals noted at birth and at 1 week (Figure 4B) and 2 weeks after birth. Morphometry confirmed reduction in this cell population in the anterior and intermediate lobes to less than $50 \%$ of controls at all ages examined.

Loss of Ikaros impairs pituitary-directed adrenocortical function. To examine the functional consequences of disrupted Ikaros signaling on pituitary corticomelanotroph development, we compared the hormonal (Figure 5) and developmental profiles of Ikaros-null mice with heterozygous and wild-type $(+/+)$ control littermates. Homozygous Ikaros-null mice demonstrated the lowest levels of ACTH in the systemic circulation (Figure 5A) and exhibited lighter fur color, consistent with a loss of POMCderived melanocyte-stimulating hormone (MSH). MSH levels measured by immunoassay when the mice were 3 weeks of age were also reduced in heterozygous but more significantly in Ikaros-null mice (Figure 5B).

The functional consequences of a diminished population of POMC-producing corticomelanotroph cells were evident in homozygous mice. Consistent with the trophic functions of ACTH on adrenocortical development and function, Ikaros-null mice exhibited reduced circulating corticosterone levels compared with heterozygous and wild-type littermates (Figure 5C). These changes were also reflected in reduction of adrenal gland size with striking loss of adrenocortical mass, especially in homozygous Ikaros-deficient mice (not shown).

Pituitary-adrenocortical dysfunction in Ikaros-deficient mice is not reversed by wild-type lymphocyte reconstitution. To examine the possibility that the diminished POMC production and adrenocortical insufficiency in Ikaros-deficient animals may be secondary to their altered lymphocyte development, we examined the impact of wild-type bone marrow reconstitution on the endocrine phenotype. Five weeks after adoptive transfer in neonatal mice, the proportion of splenic $\mathrm{CD}^{+}$and $\mathrm{CD}^{+} \mathrm{T}$ cells in the homozygous Ikaros-null recipients of Ikaros wild-type syngenic bone marrow 

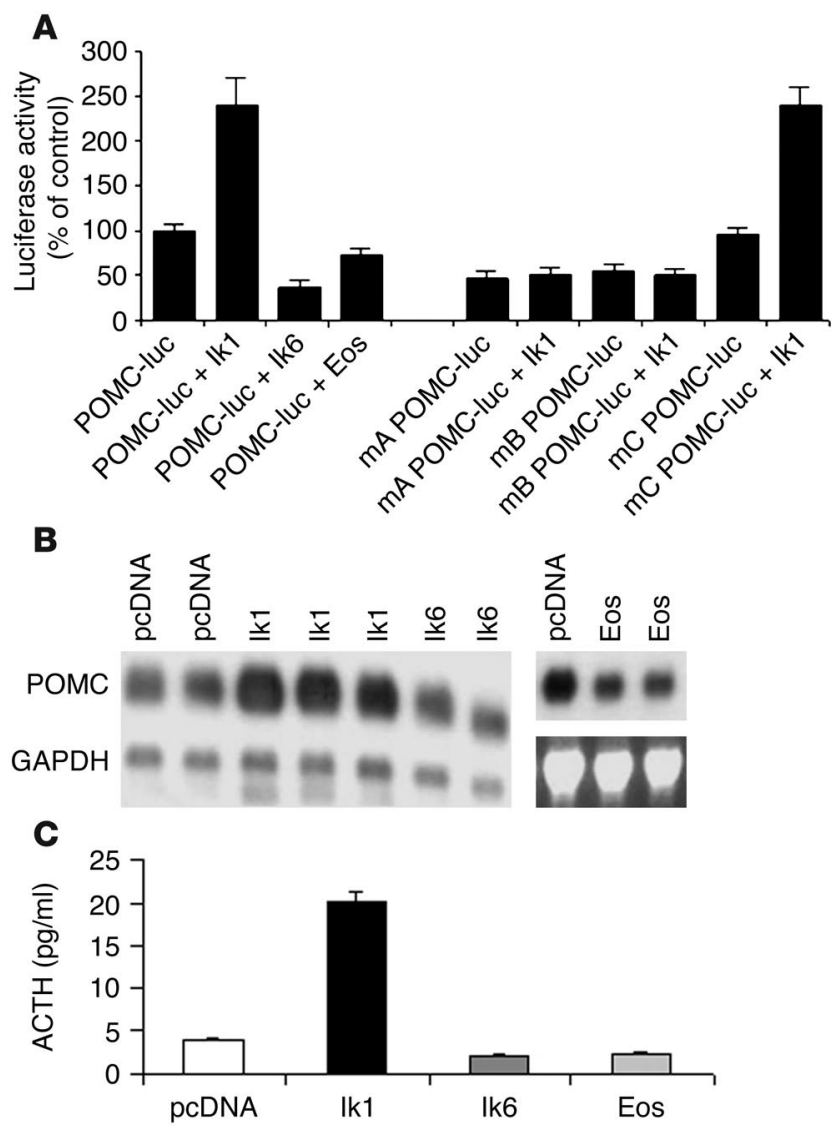

was significantly restored compared with that of vehicle-treated controls (Table 1). Despite this successful reconstitution with normal lymphocytes, the phenotype of homozygous Ikaros-deficient animals was unchanged, with persistent small size, small pituitaries, and reduction in POMC expression, and was indistinguishable from that of vehicle-treated age-matched homozygous animals. Moreover, neither heterozygous nor homozygous Ikaros-

\section{Figure 3}

Ikaros regulation of the pituitary POMC gene. (A) The effect of Ikaros on $P O M C$ promoter activity was tested in a luciferase (luc) assay. Note activation by wild-type Ik1 and loss of activity by the lkaros dominant negative isoform (Ik6) and by Eos. The functional role of the putative Ikaros-binding domains at sites $\mathrm{A}, \mathrm{B}$, and $\mathrm{C}$ in the $P O M C$ promoter was also examined. Mutation of 2 lkaros-binding sites at sites $A(m A)$ and $B(m B)$ resulted in loss of reporter activity in transfected corticotroph AtT20 cells. This effect was not seen with mutation of site $C(\mathrm{mC})$. (B) The effect of Ikaros or Eos transfection on endogenous POMC gene mRNA expression. AtT20 cells stably transfected with Ik1, Ik6, or Eos were examined by Northern blotting using a cDNA probe for the POMC gene. Densitometric analysis from multiple independent clones revealed an approximately 2.5 -fold increase in POMC/GAPDH expression in lk1transfected clones. In contrast, forced expression of Eos (right) reduces $P O M C$ expression. pcDNA, cells transfected with empty vector. (C) Conditioned culture media from Ikaros-transfected cells were examined for ACTH content by ELISA. Note significantly enhanced ACTH secretion by Ikaros-transfected cells compared with empty vector in contrast to mild reduction by Ik6 or Eos-transfected cells.

deficient animals demonstrated a significant change in serum corticosterone levels as a result of lymphocyte reconstitution (Figure 5D). These data demonstrate the direct role of Ikaros in pituitary corticotroph development and function independent of its influence on lymphopoiesis.

Glucocorticoid treatment rescues Ikaros-deficient mice. Recognizing that Ikaros mutant mice exhibit adrenocortical insufficiency, we examined the impact of systemic hormone replacement on growth and survival of the Ikaros-null mouse. Treatment with glucocorticoid hormone compared with vehicle alone resulted in significant weight increase in Ikaros-null mice; the effect was present but less evident in heterozygous animals (Figure 6A). By comparison, the same treatment paradigm had no significant impact on the growth of wild-type mice.

Overall, homozygous Ikaros-null mice exhibit diminished life expectancy with nearly $5 \%$ mortality at birth, $40 \%$ by 3 weeks of age, and $75 \%$ by 6 weeks of age (Figure 6B). Given the recognized functions of Ikaros on immune cell development and function,

\section{Figure 4}

Loss of Ikaros impairs pituitary corticomelanotroph development and ACTH expression. (A) The pituitaries of Ikaros-null mice $(\mathrm{KO})$ at E17.5 were compared with age-matched controls from heterozygous (HET) and wild-type littermates as indicated. The sections were taken from the midline of the gland and include the sphenoid bone (S) in the midline below the gland. Note the normal onset and distribution of the corticomelanotroph-specific Tpit factor (upper panels) but reduced ACTH reactivity (lower panels) in heterozygous mice and near complete absence of ACTH in homozygous mice. (B) By 1 week of age, immunocytochemical examination reveals persistent loss of ACTH reactivity in the pituitary of Ikaros-null mice compared with wild-type control littermates. The heterozygous (HET) animals also showed loss of ACTH immunoreactivity, but the glands were larger than those of homozygous animals, and the striking loss involved the intermediate lobe (arrows) that is separated from the anterior lobe by the residual Rathke's cleft $\left(^{*}\right)$ in the mid-portion of the gland. Original magnification, $\times 63$.
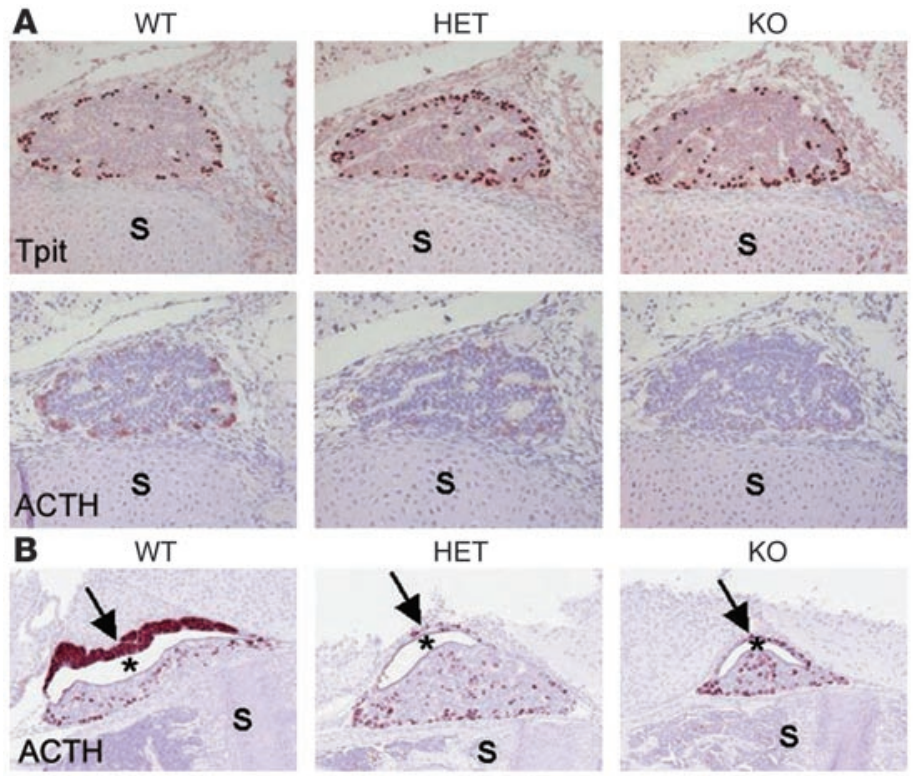

$\mathrm{KO}$

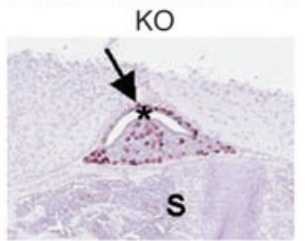


A
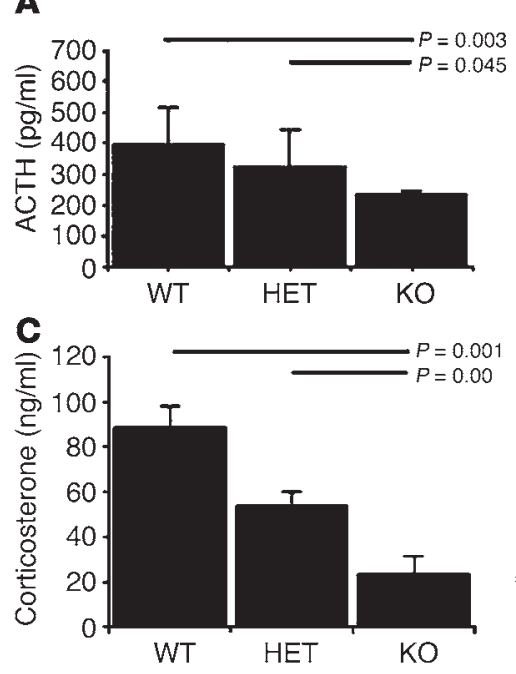

Figure 5

Disrupted corticomelanotroph development in Ikaros-deficient mice impairs pituitary-adrenocortical function. Levels of circulating hormones of the pituitary-adrenal axis including the POMC-derived peptides ACTH (A) and MSH (B) and the ACTH-dependent adrenocortical hormone corticosterone (C) were measured by immunoassay in Ikaros-null $(n=8)$, heterozygous $(n=31)$, and wild-type littermates $(n=18)$ at 3 weeks of age. The reductions in $\mathrm{ACTH}, \mathrm{MSH}$, and corticosterone levels were most pronounced in Ikaros-null mice, as illustrated by the horizontal-bar comparisons. (D) Neither lymphocyte reconstitution nor treatment with vehicle changed circulating corticosterone levels in Ikaros-deficient animals. Data are from animals described in Table 1 and reflect the impact of reconstitution with wild-type marrow cells 5 weeks after intrahepatic injection.

we performed complete organ surveys in search of opportunistic infections or malignancy. However, we found no evidence of either of these conditions to explain the observed mortality at these stages of development. Moreover, hormone treatment with glucocorticoids resulted in enhanced survival. In particular, $100 \%$ of Ikaros-null mice treated with the adrenocortical hormone $(n=7)$ survived beyond 6 weeks of age. By comparison, none of the vehicle-treated homozygous mice $(n=8)$ survived beyond the same time point.

\section{Discussion}

We present here what we believe to be the first evidence that Ikaros is directly involved in the development and function of the endocrine pituitary-adrenocortical system. Gene targeting experiments have firmly established that nuclear factors encoded by the Ikaros gene are essential for normal lymphoid development (12). Indeed, mice homozygous for a null mutation in the Ikaros gene exhibit severely impaired $\mathrm{B}$ and $\mathrm{T}$ cell differentiation $(13,14)$. In addition to its role in differentiation, Ikaros has also been suspected to play an important role in regulating cell proliferation. Heterozygous Ikaros mice exhibit hyperactive $\mathrm{T}$ cell receptor-mediated proliferative responses and eventually develop leukemias and lymphomas $(15,16)$, consistent with a dose-related effect of action. Our data indicate that Ikaros is also an essential direct regulator of normal pituitary corticotroph development, which parallels its role in lymphocytes.

We have previously demonstrated that Ikaros targets the FGFR4 promoter, which likely plays a role, along with other FGFRs (17), in normal pituitary development. However, we recognized that FGFR4 cannot be the only target of Ikaros in the pituitary, since an FGFR4-null mouse model has not shown evidence of significant pituitary dysgenesis (18). This is not surprising, given the marked redundancy of FGFRs and the fact that the pituitary gland expresses FGFR1, -2, and -3 (17).

Consistent with the striking morphologic alterations in the pituitaries of Ikaros-null mice, our data show that Ikaros targets the principal hormone gene product of corticomelanotrophs, POMC. The $P O M C$ promoter contains 5 potential Ikaros-binding sites. Two of these, site A (-451/-420) and site B (-163/-137), showed specific binding, complex formation, and interaction with an Ikarosspecific antibody. Mutational analysis confirmed the functional importance of these 2 proximal Ikaros-binding sites to POMC promoter activity. These sites are within close proximity (see Figure 2A) upstream and downstream of the recently identified Tpit/Pitx1 regulatory element (19).

The pituitary gland has provided unique insights into the molecular mechanisms and regulatory factors controlling both gene transcription and cell differentiation. The T-box factor Tpit was found to be restricted to POMC-expressing corticomelanotroph lineage (19). It activates $P O M C$ gene transcription in cooperation with contiguously bound Pitx 1 as part of the same regulatory element. Tpit activates transcription by recruiting the

\section{Table 1}

Impact of bone marrow transplantation on splenic lymphocytes in Ikaros-deficient mice

WT

\begin{tabular}{lcccc} 
& \multicolumn{2}{c}{$\begin{array}{c}\text { Vehicle } \\
(\boldsymbol{n}=\mathbf{4})\end{array}$} & \multicolumn{2}{c}{$\begin{array}{c}\text { Reconstituted } \\
(\boldsymbol{n}=\mathbf{3})\end{array}$} \\
Spleen T cells $(\%)$ & $\mathrm{CD} 4^{+}$ & $\mathrm{CD} 8^{+}$ & $\mathrm{CD} 4^{+}$ & $\mathrm{CD} 8^{+}$ \\
Mean & 12.97 & 3.18 & 13.10 & 4.47 \\
SEM & 1.28 & 0.35 & 2.65 & 1.37
\end{tabular}

Heterozygous

\begin{tabular}{cccr}
\multicolumn{2}{c}{$\begin{array}{c}\text { Vehicle } \\
(\boldsymbol{n}=\mathbf{6})\end{array}$} & \multicolumn{2}{c}{$\begin{array}{c}\text { Reconstituted } \\
(\boldsymbol{n}=\mathbf{3})\end{array}$} \\
$\mathrm{CD} 4^{+}$ & $\mathrm{CD} 8^{+}$ & $\mathrm{CD} 4^{+}$ & $\mathrm{CD} 8^{+}$ \\
13.65 & 4.07 & 12.88 & 4.82 \\
1.37 & 0.50 & 1.25 & 1.09
\end{tabular}

\begin{tabular}{cccc}
\multicolumn{4}{c}{ Homozygous } \\
\multicolumn{2}{c}{$\begin{array}{c}\text { Vehicle } \\
(\boldsymbol{n}=\mathbf{2})\end{array}$} & \multicolumn{2}{c}{$\begin{array}{c}\text { Reconstituted } \\
(\boldsymbol{n}=\mathbf{3})\end{array}$} \\
$\mathrm{CD} 4^{+}$ & $\mathrm{CD} 8^{+}$ & $\mathrm{CD} 4^{+}$ & $\mathrm{CD} 8^{+}$ \\
4.90 & 5.85 & 28.31 & 22.81 \\
0.52 & 3.11 & 2.85 & 6.63
\end{tabular}


A

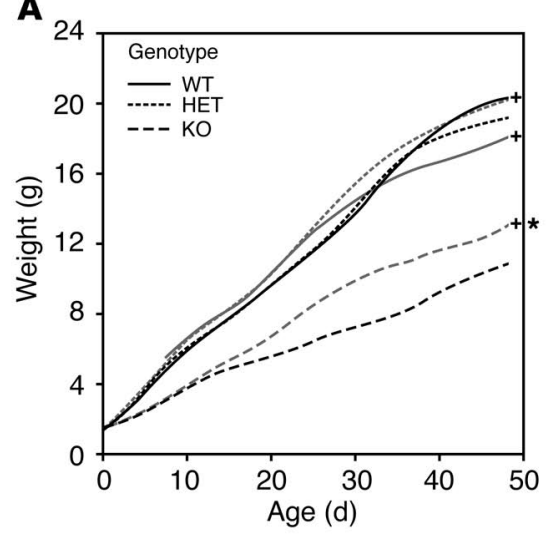

B

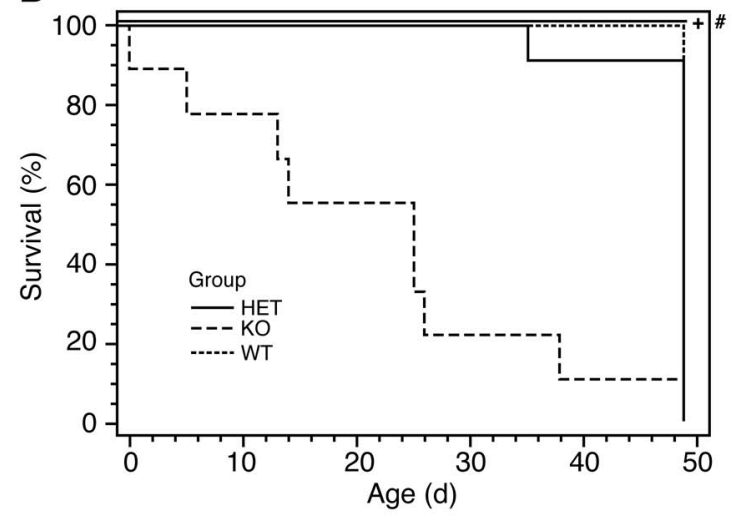

Figure 6

Disrupted pituitary-adrenocortical function in Ikaros-deficient mice contributes to impaired growth and diminished survival. (A) Health status and weight were recorded daily. Compared with Ikaros heterozygous and wild-type control littermates, Ikaros-null mice exhibit growth retardation from birth. Treatment with glucocorticoid hormone (+) compared with vehicle alone resulted in significant weight increase in lkaros-null mice, an effect not as evident in heterozygous animals. No significant impact of glucocorticoid treatment was observed in wild-type control littermates. Values shown represent the mean weights in grams and, where statistically significant $(P<0.02)$, treatment effects are denoted by an asterisk. (B) Kaplan-Meier curve depicting the diminished survival of homozygous Ikaros-deficient mice treated with vehicle alone (dashed line; $n=8$ ). The increased mortality was reversed with complete survival in hormone-treated lkaros-null mice beyond 6 weeks as indicated by the solid line $(n=7)$. ${ }^{\#} P<0.05$.

SRC/p160 coactivators to its cognate DNA target in the POMC promoter (20). Unlike Ikaros-null mice, Tpit-deficient mice have almost no POMC-reactive cells in the pituitary $(11,19)$. Corticotroph differentiation is normal in Ikaros-null mice, as determined by expression of Tpit in a large number of cells; however, the intensity of POMC expression in these cells is markedly reduced from E17.5, and after birth there is an evident reduction of this cell population. Consistent with this finding, the animals have reduced circulating corticosterone, which demonstrates the magnitude of the reduction, since as little as $10-20 \%$ of pituitary tissue mass can maintain hormonal homeostasis $(3,4)$. The phenotypic differences between the 2 models suggest that Ikaros, unlike Tpit, is not required for corticomelanotroph cell differentiation but rather plays a modulatory role in hormone gene expression and cell population expansion.

The formation of Ikaros homo- and heterodimers among the DNA-binding Ikaros family members increases their affinity for DNA, whereas heterodimers between the DNA-binding isoforms and non-DNA-binding isoforms are unable to bind DNA. Thus, Ikaros proteins with fewer than $3 \mathrm{~N}$-terminal zinc fingers can negatively interfere with the activity of Ikaros isoforms that bind DNA $(21,22)$. Histones have been shown to be underacetylated in the vicinity of Ikaros recruitment sites, while the histone deacetylase (HDAC) inhibitor trichostatin abrogates transcriptional repression mediated by Ikaros (23). An abundance of the non-DNA-binding Ikaros isoforms could result in deregulated expression of other target genes that are essential for normal pituitary development and maturation. Indeed, when bound to Ikaros-binding sites, only those isoforms with DNA-binding domains in cis are able to activate gene transcription $(21,22,24)$. In contrast, Ikaros represses transcription when recruited to DNA through a heterologous DNA-binding domain (23). This repression is mediated through at least 2 main repression domains at the $\mathrm{N}$ - and $\mathrm{C}$-termini that interact with HDAC 1 and 2 containing pendent corepressor CtBP. However, mutations that block Ikaros/CtBP interactions do not abolish Ikaros's repressive functions. Instead, Ikaros also interacts with the CtBP-interacting protein (CtIP) (27). Interestingly, CtIP's association with Ikaros does not require $\mathrm{CtBP}$ but relies heavily on interaction with $\mathrm{Rb}$. The Ikaros/ $\mathrm{Rb}$ interaction is of potential relevance in the pituitary. $\mathrm{Rb}$ is pivotal in suppressing E2F-dependent transcription and consequently G1/S cell cycle transition. Mice with heterozygous Rb mutations develop pituitary tumors of the corticomelanotroph lineage (28). These data raise questions about the participation of Ikaros in deregulating key components of pituitary cell cycle control that are implicated in pituitary growth (29).

Ikaros can also function as a transcription activator. It is noteworthy that Ikaros-mediated gene activation with localization in heterochromatin complex has been described (30). In this model, Ikaros is in direct association with its target genes in a predominantly restrictive chromatin environment that houses tightly regulated genes (31). POMC is an example of a tightly regulated gene that is typically repressed but may be activated under unique conditions when specific activators (such as Tpit) as well as other factors including Ikaros are coexpressed. Under such conditions, Ikaros functions as a potentiator by remodeling a densely packaged chromatin environment, presumably facilitating activator access during pituitary development.

The identification of Ikaros as a factor involved in the regulation of the POMC-ACTH- adrenal axis assigns new functions to this zinc finger protein. Ikaros's role as a mediator of lymphopoietic cell differentiation parallels its effects on pituitary cell differentiation. Given the role of Ikaros in lymphoid cell development, leukemia, and immune functions (31), the current findings of Ikaros in pituitary development, POMC hormone regulation, and corticomelanotroph function provide new insights into the transcriptional mechanisms at the interface of neuro-endocrine-immune interactions. 


\section{Methods}

Cell culture. Mouse corticomelanotroph AtT20 and pro-B lymphocytic cells were propagated in DMEM (Life Technologies Inc.) with a high level of glucose supplemented with 10\% FBS (Sigma-Aldrich), 2 mM glutamine, $100 \mathrm{IU} / \mathrm{ml}$ penicillin, and $100 \mu \mathrm{g} / \mathrm{ml}$ streptomycin.

Plasmids. The expression vectors encoding full-length Ikaros (CDM8-Ik1) and dominant negative Ikaros 6 (CDM8-Ik6) were generously provided by K. Georgopolous (Harvard Medical School, Charlestown, Massachusetts, USA). The Eos-encoding vector pcDNA3.1-Eos was generously provided by M. Crossley (University of Sydney, New South Wales, Australia). The orientation and sequence of all constructs were verified by restriction analysis and nucleotide sequencing.

Promoter analyses. Promoter predictions were performed with the assistance of The Transcription Factor Database TRANSFAC 6.0 (http://www. gene-regulation.com; BIOBASE $\mathrm{GmbH}$ ). The convention for sequence coordinates with +1 as the first base of the coding sequence in exon 1 was adopted. The mouse POMC -543-bp luciferase reporter was a generous gift of J. Drouin (University of Montreal, Montreal, Quebec, Canada.).

Site-directed mutagenesis. Site-directed mutagenesis was performed using a QuikChange Site- Directed Mutagenesis Kit (Stratagene) following the manufacturer's instructions. We introduced mutation of the Ikaros transcription binding site-CGGGAA-substituted by-CGTTAA-into the POMC promoter fragment $\mathrm{P}(-543)$-Luc construct by using mutagenic primers for each of the 5 potential Ikaros-binding sites identified in this promoter (Figure 2A). All mutations were confirmed by nucleotide sequencing.

Transfection and luciferase assays. Plasmid reporters were prepared by column chromatography (QIAGEN) for sequencing and transfections. Cells were transfected by the Lipofectamine Method (Invitrogen Corp.) according to the manufacturer's protocol. Cells were plated into 6-well cluster dishes $\left(7 \times 10^{5}\right.$ cells per well), transfected the following day with $3 \mu \mathrm{l}$ or $5 \mu \mathrm{l} /$ well of lipofectamine and 1 or $2 \mu \mathrm{g}$ of DNA per well as indicated. We kept the total amount of transfected DNA constant by adding empty vector. Transfection efficiency was monitored by simultaneous cotransfection with a $\beta$-gal control expression plasmid cytomegalovirus (CMV)- $\beta$-gal (20 ng/well). Forty-eight hours after transfection, cells were lysed in buffer containing $25 \mathrm{mM}$ glycylglycine, $15 \mathrm{mM} \mathrm{MgSO}_{4}, 4 \mathrm{mM}$ EGTA, 1\% Triton $\mathrm{X}-100$, and $1 \mathrm{mM}$ DTT. Luciferase activity was measured for 20 seconds in a luminometer. We measured $\beta$-gal activity to normalize for variations in transfection efficiency. Promoter activity of each construct was expressed as firefly luciferase/ $\beta$-gal activity. Each experiment was independently performed on 3 separate occasions with triplicate wells in each experiment.

Preparation of nuclear extracts. We prepared nuclear extracts by washing cells in $\times 1$ PBS and lysing them in $100 \mu$ l buffer containing $10 \mathrm{mM}$ HEPES, $\mathrm{pH}$ 7.9, 1 mM DTT, 1 mM EDTA, $60 \mathrm{mM} \mathrm{KCl}, 0.5 \%$ NP-40, 1 mM PMSF for 5 minutes on ice. The pellet was resuspended into $100 \mu \mathrm{l}$ of the nuclear resuspension buffer $(0.25 \mathrm{mM}$ Tris- $\mathrm{HCl}, \mathrm{pH} 7.8,60 \mathrm{mM} \mathrm{KCl}, 1 \mathrm{mM}$ DTT, $1.5 \mathrm{mM}$ PMSF) and lysed with 3 cycles of freezing and thawing to $37^{\circ} \mathrm{C}$. After centrifugation at $13,000 \mathrm{rpm}$ for 10 minutes at $4^{\circ} \mathrm{C}$, the clear supernatant was collected for further analysis. Protein concentrations were determined by the Bio-Rad method (Bio-Rad Laboratories).

EMSA. We labeled oligonucleotides with $\left[\gamma^{-32} \mathrm{P}\right] \mathrm{dATP}$ using the T4 polynucleotide kinase (Invitrogen Corp.). Five micrograms of nuclear protein extracts and $2 \mathrm{ng}$ of labeled oligonucleotides were allowed to bind for 30 minutes at room temperature in a final volume of $20 \mu \mathrm{l}$ of binding buffer [20 mM HEPES, pH 7.9, 50 mM KCl, 1 mM EDTA, 1 mM DTT, $0.5 \mathrm{mM} \mathrm{MgCl}_{2}, 2 \%$ glycerol, and $0.5 \mu \mathrm{g}$ poly(dI-dC)] (Pharmacia Corp). Protein-DNA complexes were resolved in $4 \%$ polyacrylamide gels containing $\times 0.5$ tris-borate EDTA (TBE). Five double-stranded oligonucleotide fragments containing the potential Ikaros-binding sites in the POMC promoter were synthesized (Sigma-Aldrich) and used as probes and for competition in EMSAs as follows: Ikaros binding site A (-448 to -431$)$, 5'-AACACTGGGGAAATCTGA-3'; Ikaros binding site B (-159 to -142), sense: $5^{\prime}$-CCCCGACCGGGAAGCCCC-3'; Ikaros binding site C (-112 to -95$), 5^{\prime}$-GTGGCCGGGGATTCGCTT-3'; Ikaros binding site D (-12 to +7), 5'-GTGACAGGGACCAAACGG-3'; Ikaros binding site E (-12 to $+16), 5^{\prime}$-ACCAAACGGGAGGCGACG-3', and their mutant forms (mA, $\mathrm{mB}, \mathrm{mC}, \mathrm{mD}$ and $\mathrm{mE}$ ), where the core Ikaros binding site (-GGGAA-) was substituted by -GTTAAA-. Other probes and competitor oligonucleotides containing transcription binding sites were as follows: Sp1, 5'-ATTCGATCGGGGCGGGGCGAGC-3' and its complementary strand; Ikaros, 5'-AAGAAGCGGGAGTGACAGG-3' and its complementary strand; Pit1, $5^{\prime}$-TGTCTTCCTGAATATGAATAAGAAATA-3' and its complementary strand; Ap-1, 5'-CGC TTGATGAGTCAGCCGGAA-3' and its complementary strand; Ap-2, 5'-GATCGAACTGACCGCCCGCGGCCCGT-3' and its complementary strand. The complementary strands were annealed in the annealing buffer (10 mM Tris-Cl, pH 8.0, $50 \mathrm{mM} \mathrm{NaCl}, 1 \mathrm{mM}$ EDTA).

Gel shift probes were purified with a G50 spin column (Amersham Biosciences) after radiolabeling. For competition assay, 10 or $100 \mathrm{M}$ excess of unlabeled fragment was added as competitor DNA. Supershifting was achieved using 2 Ikaros antibodies: a mouse monoclonal antibody (kindly provided by K. Georgopolous) and a polyclonal antibody (kindly provided by S. Smale, UCLA, Los Angeles, California, USA). Both antibodies recognize the C-terminal fragments of Ikaros proteins. Supershifting with Eos was performed using a specific antibody recognizing Eos (kindly provided by M. Crossley). Antibodies to Pit-1, Rb, and Sp1 were used as described previously (7). Antibodies were used at different concentrations and were applied 30 minutes before addition of radiolabeled probe. Samples were electrophoresed and gels dried under vacuum and autoradiographed.

RNA isolation and Northern blotting. PolyA-enriched RNA was prepared from exponentially growing cells $\left(2-5 \times 10^{7}\right)$ using a FastTrack 2.0 mRNA Isolation Kit (Invitrogen Corp.) following the manufacturer's instructions. Two micrograms of polyA ${ }^{+}$RNA were electrophoresed on a $1 \%$ formaldehyde-agarose gel and transferred to a nylon membrane. Hybridization was performed using probes labeled randomly (Roche Diagnostics Corp.) with $\left[\alpha-{ }^{32} \mathrm{P}\right]-\mathrm{dCTP}$ from the cDNAs of Ikaros, Eos, POMC, and GAPDH. The Ikaros probe consisted of a 1,200-bp fragment encoding the C-terminus BamHI-EcoRV fragment of the Ikaros cDNA. The Eos probe was a 587-bp BamHI-HindIII fragment of the mouse Eos cDNA. The POMC probe was generated by RT-PCR using the specific primers (sense: $5^{\prime}$ - ATGCCGAGATTCTGCTACAG- 3'; antisense: 5' - TCACTGGCCCTTCTTGTGCG- $3^{\prime}$ to produce a 708-bp fragment from POMC cDNA, and the GAPDH probe was made from RT-PCR with the specific primers to produce a $687-\mathrm{bp}$ fragment. Northern blots were hybridized in the $\times 1$ hybridization buffer (Sigma-Aldrich) at $65^{\circ} \mathrm{C}$ overnight with rotation in oven, then washed and exposed to film. RNA sizes were calculated using the marker 0.24-9.5 kb RNA Ladder (Invitrogen Corp.).

Western blotting. Forty micrograms of whole lysates were separated on $10 \%$ SDS denaturing polyacrylamide gels, transferred onto nylon membrane (Millipore) at $100 \mathrm{~V}$ for 1 hour at room temperature. Blots were incubated with a mouse monoclonal antibody (4E9; kindly provided by K. Georgopolous) that recognizes the C-terminal fragments of Ikaros proteins (22) or POMC (DakoCytomation) at 1:2,000 dilution in PBS-5\% nonfat milk with $0.1 \%$ Tween at $4{ }^{\circ} \mathrm{C}$ overnight, after which they were washed with PBSTween-20 four times for 10 minutes each at room temperature and incubated with secondary antibody of peroxidase-conjugated goat antimouse $\operatorname{IgG}(1: 2,000)$ for 1 hour at room temperature with agitation. Proteins were detected using a chemiluminescence method (Amersham Biosciences).

Ikaros-deficient mice. Ikaros-null mice were generated by Georgopolous et al. (Harvard Medical School, Charlestown, Massachusetts, USA). Deletion of the exon 7-encoded Ikaros dimerization domain results in an unstable 
and undetectable protein (13). Mice were propagated on the original C57BL/ 6 background. We monitored germline allelic transmission by PCR analysis using tail DNA and previously described primers (13). Specimens for blood and tissue analyses were obtained from embryos at various times during gestation and from adult mice. The care and handling of animals were approved by the Institutional Animal Care Facilities at the Ontario Cancer Institute, where the animals were housed.

Morphologic studies of the pituitary. In order to localize prenatal and neonatal pituitaries, we took sagittal sections of the intact head of the fetus, using the cartilage of the sphenoid bone as a landmark as previously described $(32,33)$. Consecutive serial sections from the midline to the lateral aspect of the pituitary were collected. Pituitary size was estimated in postnatal mice by the summation of scan area cross-sections starting from the midline portion all the way through the lateral wing of the pituitary. Serial sections were stained with $\mathrm{H} \& \mathrm{E}$ or with antibodies to localize the various pituitary hormones as described previously (34) and to identify transcription factors using anti-sera described above and an antibody to Tpit (kindly provided by J. Drouin). Immunolocalization was detected with the streptavidin-biotin-peroxidase complex technique and 3,3'-diaminobenzidine (DAB) staining. Colocalization with pituitary hormones was performed with double staining as previously described (34). As a negative control, we used normal mouse ascites or normal rabbit serum, replacing the primary monoclonal or polyclonal antibody, respectively. Additional negative controls included preabsorption of the primary antibody or antiserum with purified antigen. We carried out morphometry to determine the areas of immunostained cells as a proportion of pituitary area.

Hormone measurements and administration. Secreted ACTH was measured by a 2 -site ELISA according to the manufacturer's (Biomerica Inc.) protocol. A corticosterone enzyme immunoassay was used to reflect adrenocortical hormone secretion using a commercially available kit (ALPCO Diagnostics). We commenced hormone rescue treatment when mice were 5 days of age using the synthetic glucocorticoid dexamethasone (Sigma-
Aldrich). This was administered intraperitoneally at a dose of $0.05 \mathrm{mg} / \mathrm{kg}$ every 2 days for 6 weeks. The dosing regimen was based on titration studies and utilized the maximum dose that was tolerated without weight gain in wild-type control littermates.

Hematopoietic cell repopulation. Bone marrow was prepared from 6-week-old wild-type Ikaros littermates. Following lysis of red blood cells, the resulting cell suspension was filtered through a $70-\mu \mathrm{m}$ cell strainer, and $10^{6}$ cells were injected intrahepatically into newborn Ikaros-deficient and -sufficient animals as described previously (35). Bone marrow recipients were sacrificed 5 weeks after reconstitution for examination of pituitary morphology and circulating hormone measurements. Lymphocyte reconstitution was assessed in the spleen and thymus of bone marrow recipients by multicolor cell-surface immunofluorescence and FACS analysis, as previously described (36).

\section{Acknowledgments}

We thank K. Georgopoulos for generously providing the Ikarosnull mice and Ikaros antibody, S. Smale for Ikaros antiserum, and M. Crossley for Eos reagents. We also thank J. Drouin for the Tpit antibody and for insightful discussions. The technical assistance of K. So is also gratefully acknowledged. This work was supported by the Canadian Institutes of Health Research and the Toronto Medical Laboratories.

Rene Mader and Shunjiang Yu contributed equally to this work.

Received for publication June 21, 2004, and accepted in revised form January 11, 2005.

Address correspondence to: Sylvia L. Asa, Department of Pathology, University Health Network, 610 University Avenue 4-302, Toronto, Ontario M5G-2M9, Canada. Phone: (416) 946-2099; Fax: (416) 946-6579; E-mail: sylvia.asa@uhn.on.ca.
1. Chrousos, G.P. 1995. The hypothalamic-pituitaryadrenal axis and immune-mediated inflammation. N. Engl. J. Med. 332:1351-1362.

2. Turnbull, A.V., and Rivier, C.L. 1999. Regulation of the hypothalamic-pituitary-adrenal axis by cytokines: actions and mechanisms of action. Physiol. Rev. 79:1-71.

3. Asa, S.L., and Ezzat, S. 1998. The cytogenesis and pathogenesis of pituitary adenomas. Endocr. Rev. 19:798-827.

4. Asa, S.L., and Ezzat, S. 1999. Molecular determinants of pituitary cytodifferentiation. Pituitary. 1:159-168.

5. Molnar, A., et al. 1996. The Ikaros gene encodes a family of lymphocyte-restricted zinc finger DNA binding proteins, highly conserved in human and mouse. J. Immunol. 156:585-592.

6. Georgopoulos, K., Winandy, S., and Avitahl, N. 1997. The role of the Ikaros gene in lymphocyte development and homeostasis. Annu. Rev. Immunol. 15:155-176.

7. Yu, S., Asa, S.L., and Ezzat, S. 2002. Fibroblast growth factor receptor 4 is a target for the zinc-finger transcription factor Ikaros in the pituitary. $\mathrm{Mol}$. Endocrinol. 16:1069-1078.

8. Armstrong, E., Partanen, J., Cannizzaro, L., Huebner, K., and Alitalo, K. 1992. Localization of the fibroblast growth factor receptor-4 gene to chromosome region 5q33-qter. Genes Chromosomes Cancer. 4:94-98.

9. Ezzat, S., Yu, S., and Asa, S.L. 2003. Ikaros isoforms in human pituitary tumors: distinct localization, histone acetylation, and activation of the $5^{\prime}$ fibroblast growth factor receptor-4 promoter. Am. J. Pathol. 163:1177-1184.

10. Yu, S., Asa, S.L., Weigel, R.J., and Ezzat, S. 2003. Pituitary tumor AP-2alpha recognizes a cryptic promoter in intron 4 of fibroblast growth factor receptor 4. J. Biol. Chem. 278:19597-19602.

11. Pulichino, A.M., et al. 2003. Human and mouse TPIT gene mutations cause early onset pituitary ACTH deficiency. Genes Dev. 17:711-716.

12. Cortes, M., Wong, E., Koipally, J., and Georgopoulos, K. 1999. Control of lymphocyte development by the Ikaros gene family. Curr. Opin. Immunol. 11:167-171.

13. Wang, J.H., et al. 1996. Selective defects in the development of the fetal and adult lymphoid system in mice with an Ikaros null mutation. Immunity. 5:537-549.

14. Winandy, S., Wu, L., Wang, J.H., and Georgopoulos, K. 1999. Pre-T cell receptor (TCR) and TCR-controlled checkpoints in $\mathrm{T}$ cell differentiation are set by Ikaros. J. Exp. Med. 190:1039-1048.

15. Winandy, S., Wu, P., and Georgopoulos, K. 1995. A dominant mutation in the Ikaros gene leads to rapid development of leukemia and lymphoma. Cell. 83:289-299.

16. Avitahl, N., et al. 1999. Ikaros sets thresholds for T cell activation and regulates chromosome propagation. Immunity. 10:333-343.

17. Abbass, S.A.A., Asa, S.L., and Ezzat, S. 1997. Altered expression of fibroblast growth factor receptors in human pituitary adenomas. J. Clin. Endocrinol. Metab. 82:1160-1166.

18. Weinstein, M., Xu, X., Ohyama, K., and Deng, C.X. 1998. FGFR-3 and FGFR-4 function cooperatively to direct alveogenesis in the murine lung. Development. 125:3615-3623.

19. Lamolet, B., et al. 2001. A pituitary cell-restricted $\mathrm{T}$ box factor, Tpit, activates POMC transcription in cooperation with Pitx homeoproteins. Cell. 104:849-859.

20. Maira, M., et al. 2003. The T-box factor Tpit recruits
$\mathrm{SRC} / \mathrm{p} 160$ co-activators and mediates hormone action. J. Biol. Chem. 278:46523-46532.

21. Molnar, A., and Georgopoulos, K. 1994. The Ikaros gene encodes a family of functionally diverse zinc finger DNA-binding proteins. Mol. Cell. Biol. 14:8292-8303

22. Sun, L., Liu, A., and Georgopoulos, K. 1996. Zinc finger-mediated protein interactions modulate Ikaros activity, a molecular control of lymphocyte development. EMBO J. 15:5358-5369.

23. Koipally, J., Renold, A., Kim, J., and Georgopoulos, K. 1999. Repression by Ikaros and Aiolos is mediated through histone deacetylase complexes. EMBOJ. 18:3090-3100.

24. Wargnier, A., et al. 1998. Down-regulation of human granzyme B expression by glucocorticoids. Dexamethasone inhibits binding to the Ikaros and AP-1 regulatory elements of the granzyme B promoter. J. Biol. Chem. 273:35326-35331.

25. Kim, J., et al. 1999. Ikaros DNA-binding proteins direct formation of chromatin remodeling complexes in lymphocytes. Immunity. 10:345-355.

26. Perdomo, J., Holmes, M., Chong, B., and Crossley, M. 2000. Eos and pegasus, two members of the ikaros family of proteins with distinct DNA binding activities. J. Biol. Chem. 275:38347-38354.

27. Koipally, J., and Georgopoulos, K. 2002. Ikaros$\mathrm{CtIP}$ interactions do not require $\mathrm{C}$-terminal binding protein and participate in a deacetylaseindependent mode of repression. J. Biol. Chem. 277:23143-23149.

28. Jacks, T., et al. 1992. Effects of an $R b$ mutation in the mouse. Nature. 359:295-300.

29. Asa, S.L., and Ezzat, S. 2002. The pathogenesis of pituitary tumours. Nat. Rev. Cancer. 2:836-849.

30. Sabbattini, P., et al. 2001. Binding of Ikaros to the 
lambda5 promoter silences transcription through a mechanism that does not require heterochromatin formation. EMBO J. 20:2812-2822.

31. Georgopoulos, K. 2002. Haematopoietic cell-fate decisions, chromatin regulation and ikaros. Nat. Rev. Immunol. 2:162-174.

32. Bennani-Bäiti, I.M., et al. 1998. DNase I-hypersensitive sites I and II of the human growth hormone locus control region are a major developmental activator of somatotrope gene expression. Proc.
Natl. Acad. Sci. U. S. A. 95:10655-10660

33. Shewchuk, B.M., Asa, S.L., Cooke, N.E., and Liebhaber, S.A. 1999. Pit-1 binding sites at the somatotrope-specific DNase I hypersensitive sites I, II of the human growth hormone locus control region are essential for in vivo hGH-N gene activation. J. Biol. Chem. 274:35725-35733.

34. Asa, S.L., Coschigano, K.T., Bellush, L., Kopchick, J.J., and Ezzat, S. 2000. Evidence for growth hormone $(\mathrm{GH})$ autoregulation in pituitary somatotrophs in
GH antagonist-transgenic mice and GH receptordeficient mice. Am. J. Pathol. 156:1009-1015.

35. Nichogiannopoulou, A., Trevisan, M., Neben, S., Friedrich, C., and Georgopoulos, K. 1999. Defects in hemopoietic stem cell activity in Ikaros mutant mice. J. Exp. Med. 190:1201-1214.

36. Poussier, P., Ning, T., Banerjee, D., and Julius, $M$ 2002. A unique subset of self-specific intraintestinal T cells maintains gut integrity. J. Exp. Med. 195:1491-1497. 